\title{
Tumour Angiogenesis: A Growth Area-From John Hunter to Judah Folkman and Beyond
}

\author{
J. A. Stephenson, ${ }^{1}$ J. C. Goddard, ${ }^{2}$ O. Al-Taan, ${ }^{3}$ A. R. Dennison, ${ }^{3}$ and B. Morgan ${ }^{1}$ \\ ${ }^{1}$ Department of Cancer Studies and Molecular Medicine, University Hospitals of Leicester, Leicester Royal Infirmary, \\ Leicester LE1 5WW, UK \\ ${ }^{2}$ Department of Urology, University Hospitals of Leicester, Leicester General Hospital, Gwendolen Road, Leicester LE5 4PW, UK \\ ${ }^{3}$ Department of Surgery University Hospitals of Leicester, Leicester General Hospital, Gwendolen Road, Leicester LE5 4PW, UK
}

Correspondence should be addressed to J. A. Stephenson; jastephenson@doctors.org.uk

Received 28 March 2013; Accepted 17 June 2013

Academic Editor: Kentaro Nakayama

Copyright (C) 2013 J. A. Stephenson et al. This is an open access article distributed under the Creative Commons Attribution License, which permits unrestricted use, distribution, and reproduction in any medium, provided the original work is properly cited.

\begin{abstract}
Angiogenesis is the growth of new blood vessels in the body. Abnormal angiogenesis is recognised as a "common denominator" in many disease processes, and the development of angiogenesis inhibitors holds great hope in the ongoing battle against cancer. The field of angiogenesis has roots in the Hunterian era of the late eighteenth century but did not begin to blossom until the early 1970 s when the then controversial findings and conclusions of Judah Folkman, the "father of angiogenesis," were first published. There were only 65 publications with angiogenesis in the title in the 10 years after Folkman first proposed the idea of tumour angiogenesis, compared to over 9,000 publications from the year 2000 to 2010. In this review we will explore the voyage of discovery from the first observations of John Hunter in the eighteenth century, via the struggle faced by Folkman to prove the importance of angiogenesis, and finally how his determination has led to modern angiogenesis inhibitors being used in everyday clinical practice.
\end{abstract}

\section{Angiogenesis}

Angiogenesis is the formation of new blood vessels from preexisting vessels and is a normal and highly regulated physiological process throughout the body. Since physiological angiogenesis is associated only with tissue growth, tissue repair, and the reproductive cycle, angiogenesis in normal adult tissues is a very rare event, and the endothelium of most tissues is therefore an extremely stable population of cells with very low mitotic activity [1]. Angiogenesis also occurs after implantation of the blastocyst of the embryo to the uterus. This produces the placenta $[2,3]$ and was first observed in pregnant monkeys by Hertig in 1935 [4]. In the developing embryo both angiogenesis and the earlier distinct process of vasculogenesis are required for foetal growth and viability [5].

\section{The Beginnings of Angiogenesis: From Hunter to Folkman-A Slow Beginning}

The founder of "scientific surgery" John Hunter (1728-1793), who sought to provide an experimental basis to surgical practice, first used the term angiogenesis in 1787 [1]. He stated that vessels "would appear to have more powers of perfecting themselves, when injured, than any other part of the body; for their use is almost immediate and constant, and it is they which perform the operation of restoration on the other parts, therefore they themselves must first be perfect" [6]. He noted the early appearance of new blood vessels to supply the growing antlers from the Fallow Deer's skull, observing "a soft membranous pulp shooting out from this knob which is extremely vascular" [7].

Despite this early and accurate observation from Hunter, reports of tumour angiogenesis in the next 100 years were very few and nearly all were from anatomical studies.

In the mid nineteenth century, Thiersch (1822-1895), working in Leipzig Germany, demonstrated a vigorous formation of new vessels in the stroma of carcinomas. Using vessel injection techniques, he discovered that these new vessels originated from preexisting capillaries [8]. Virchow (18211902) studied the vascular morphology of tumours in great detail [9] and at about the same time Bilroth (1829-1894), the founding father of modern abdominal surgery, noted that in 
the youngest parts of tumours there were numerous fine vessels and vascular networks, whereas the older areas of these tumours were associated with wider thrombosed and atrophied vessels [10].

Bashford and Goldmann confirmed the findings of both Hunter and Bilroth in the early twentieth century [11, 12]. Goldmann visualised the vascular networks in human and animal tumours by injecting India ink and bismuth-in-oil into the vasculature, which enabled him to study the number, form, and width of blood vessels. At a lecture to the Royal Society of Medicine in 1907 he noted that the regular distribution of blood vessels is disturbed by the invading growth of a cancer and that at the tumour periphery there was extensive new vessel formation.

Lewis used Goldmann's experimental methods in 1927. He wrongly concluded that blood vessels did not determine the growth of the tumour but rather that the tumour determined the growth and pattern of vessels, a misconception that continued until late in the 20th century and hindered the acceptance of Folkman's conclusions. He did however state that different tumours had different vascular patterns, which may be useful in diagnosis [13].

The early 1930's saw the emergence of the field of vascular biology, when E. R. Clark and E. L. Clark placed glass-windowed chambers in the rabbit ear and made exquisite drawings of the branching patterns of the blood vessels that entered the wound in the rabbit ear [14]. Later in the 1930's the theories of Goldmann were supported by work carried out by Ide and Algire. Using a rabbit tumour model, Ide inserted fragments of epithelioma into a rabbit ear. He observed that tumour growth was accompanied by infiltration of newly formed blood vessels and that neovascularisation occurred in the implanted tumours and not the controls [15]. Algire first demonstrated the observation that tumours actively attract new blood vessels in the 1940's using wound chambers [1618].

From 1940 to 1960 Green (1905-1969) was working at the forefront of the field of tissue transplantation. Greene's study on heterologous transplantation of mammalian tumours showed that rabbit adenocarcinomas transplanted into the anterior chamber of guinea pig eyes would grow if these tumours became vascularised. In those tumours that grew, he described a pinkish colouration of the tumour substance two weeks after transplantation, which represented neovascularisation. If tumour growth was delayed, he observed a lack of vascularisation [19]. Greene moved to Yale University in 1943 and became the Anthony N. Brady Professor and Chairman of the Department of Pathology in 1950. His continued work at Yale later showed that human tumours became vascularised and then grew following implantation into the anterior chamber of a guinea pig eye [20]. Using the same model, small tumour fragments often failed to gain a blood supply but when these fragments were transplanted into the vessel rich environment of muscle they increased in size after undergoing vascularisation [21]. Interestingly, Greene gained marked public prominence, not for his scientific work on transplantation and tumour growth, but for his outspoken and sceptical views of the theory that smoking was connected to lung cancer in the late 1950's. He continued to smoke and died happy at the relatively young age of 64 .

Over this period of twenty years numerous authors published data of neovascularisation of tumours implanted subcutaneously, in transplant chambers or in hamster cheek pouches. [22-26]. These studies attributed the cause of tumour neovascularisation to various factors including inflammation, vasodilatation, and increased tumour metabolism or overproduction of specific metabolites such as lactic acid.

Thus, at this early stage the concept of tumor neovascularisation was well established but hypotheses as to its causes and implications were misleading because prevailing opinion was that tumour growth did not depend on angiogenesis but that tumour vascularity was nonspecific inflammation $[27,28]$.

A key change came with the first suggestion that neovascularisation was due to hypoxia from "tumours outgrowing their blood supply" in 1962 when Folkman (1933-2008) and Frederick Becker studied tumour growth in organ culture [29].

\section{Judah Folkman: The "Father of Angiogenesis"}

Moses Judah Folkman was born in Cleveland, USA on February 24, 1933, to Rabbi Jerome Folkman and wife Bessie. Shortly after his birth the family moved to Grand Rapids, Michigan, USA. As a child Folkman was encouraged to seek knowledge, particularly in the field of science and one of the first books he read was a biography of Madame Marie Curie [30].

Folkman graduated from Harvard Medical School in 1957 and was a third year surgical resident at Massachusetts General Hospital, Boston, USA, when he was drafted by the navy in 1960 to work in the laboratory of the Naval Medical Research Institute in Bethesda, Maryland, US. While at the Naval Medical Research Institute, Folkman worked with David Long, a surgical resident from the University of Minnesota and the above-mentioned Fred Becker, a pathology resident from New York University. One of the projects they were charged with was testing freeze-dried haemoglobin solutions as an alternative to fresh blood $[27,28]$. The haemoglobin preparations were tested for the ability to sustain the viability of dog thyroid glands and, later, the growth of mouse tumour cells implanted within these dog thyroid glands within organ culture. The implanted tumours stopped growing after reaching a modest size but grew explosively if transplanted back into a mouse. Examining the tumours Folkman found a network of tiny blood vessels inside the retransplanted tumour cells, whereas there were no vessels in the original thyroid tumours [29]. In 1962 Folkman returned to his surgical residency position post in Boston inspired by what he had observed and concurrently continued experimental work to these observations and his developing theories on neovascularisation in tumors [27]. Fascinatingly, while at the Naval Medical Research Institute, Long and Folkman also discovered that sustained drug release could be achieved from silicone rubber. On discharge from the Navy, they gifted the patent "royalty-free" to the Population Council of the Rockefeller Foundation, who used 
the technology to develop an implantable sustained release contraceptive,Norplant. This technology is still used today for estradiol sustained release vaginal rings [27, 31].

After completing his residency in 1965, Folkman joined Harvard's Department of Surgery at the Boston City Hospital. In 1966, under the chairman of the department, Professor William McDermott, Folkman and colleagues developed an isolated organ perfusion system to provide a vascular bed for the study of tumour growth [32]. He continued research alongside his clinical and teaching role. In 1968, Folkman spent six months at The Philadelphia Children's Hospital as chief surgical resident prior to his appointment as "Julia Dyckman Andrus" Professor of Pediatric Surgery and surgeon-in-chief at the Children's Hospital in Boston, where he directed a laboratory that focused on angiogenesis research [27, 30]. In 1969, Folkman's hypothesis was fuelled clinically when he saw a child with a retinoblastoma. The child had a large neovascularised tumour $\left(>1 \mathrm{~cm}^{3}\right)$, which protruded from the retina into the vitreous, with numerous tiny metastases from primary tumour cells that had shed into the vitreous and aqueous humour. The metastases averaged $1.25 \mathrm{~mm}$ diameter, with a thin rim of viable tissue surrounding a necrotic core. He correctly assumed they could not become neovascularised as they were too far removed from the vascular bed and thus could not grow further [33].

This lab work and clinical observations helped Folkman develop the hypothesis that "tumour growth is angiogenesisdependant." He appreciated that for a tumour to receive enough oxygen and nutrients to promote growth beyond $2 \mathrm{~mm}$, simple diffusion was not enough and new vessels must be recruited. Along with this hypothesis he also suggested other concepts:

(1) virtually all tumours would be restricted to a microscopic size in the absence of angiogenesis,

(2) tumours would be found to secrete diffusible angiogenic molecules,

(3) tumour dormancy would result from blocked angiogenesis.

$\mathrm{He}$ also proposed the term antiangiogenesis to mean prevention of new capillary sprouts from being recruited into an early tumour implant and predicted the future discovery of angiogenesis inhibitors, suggesting that an antibody to a tumour angiogenic factor (TAF) could be an anticancer drug [32].

These ideas were widely criticised, as the prevailing opinion was that tumour growth did not depend on angiogenesis but that tumour vascularity was nonspecific inflammation $[27,28]$. Skeptics challenged Folkman's hypothesis and journal reviewers complained that the conclusions of his experiments reached beyond the data [27].

Due to the scepticism Folkman's conclusions received, it was not until 1971 that his seminal paper "Tumour angiogenesis: therapeutic implications" was published [34]. Throughout the 1970's general belief in the scientific community was that tumours grew around established capillary blood vessels and that new vessel recruitment was not possible. This was despite the published findings discussed previously from Greene's work in the 1940s. His report of new blood vessels at the border of tumours was interpreted as "inflammatory reactions of the host to dying tumour cells in the necrotic centre of the tumour" [27].

His hypothesis gained more credibility when it was backed up by work published by Folkman's postdoctoral fellow Michael Gimbrone in 1972. Utilising the eye transplant model he first demonstrated that epithelioma tumour fragments implanted into the eyes of male rabbits would not grow beyond $1 \mathrm{~mm}^{2}$ if placed away from blood vessels on the avascular anterior chamber of the eye and histology confirmed these tumours to be avascular. Secondly he showed that tumour fragments implanted directly onto the iris grew nearly 16,000 times their original size in only two weeks. The growth pattern was observed in three phases described by a sigmoid curve: an early prevascular phase rate with slow growth, then a rapid growth observed in the vascular phase leading to a slower late growth phase once the tumour filled the anterior chamber [34].

The model was then used to hypothesise that cellular contact was not required between host vessels and tumour cells for neovascularisation to occur. Tumour fragments were implanted on the cornea either in the central avascular area ( $>3 \mathrm{~mm}$ from the limbus) or on the periphery $2 \mathrm{~mm}$ from the limbal edge. The peripherally placed fragments vascularised as new capillary blood vessels grew from the limbus, invading the stroma of the avascular cornea, and reached the edge of the tumour within 8-10 days. There was no sign that the neovascularisation occurred due to inflammation as the cornea did not become opaque or oedematous. The tumours grew exponentially in threedimensions and protruded from the cornea within 2-3 weeks. The tumours in the centre of the cornea remained nonvascularised and grew slowly in two dimensions, as thin flat, translucent, intracorneal lesions until one edge extended to within $\sim 2 \mathrm{~mm}$ of the limbus, when they recruited new blood vessels and subsequently grew in three dimensions. It was suggested that a diffusible mediator or "angiogenic factor" existed which stimulated vascularisation [34-37]. This supported work produced by Greenblatt and Ehrman, which had shown that tumour-stimulated vessel growth did not require direct contact between tumour and host tissues [38, 39].

Knighton, working with Folkman in 1977, saw similar results in different animal models. An implant of Walker 256 carcinoma was injected into the chorioallantoic membrane of a chicken egg through a shell window, subsequently using the window to observe vessel growth. As previously the tumours exhibited prevascular and vascular growth phases. Unlike the previous studies this experiment placed the tumours in an area surrounded by healthy vessels. Even so, tumour growth still did not occur until host vessels penetrated the tumour. Neovascularisation always occurred by 72 hours [40].

Despite the impressive initial results from Folkman's group, his ideas were still widely criticised throughout the 1970s. The 1971 New England Journal of Medicine paper is said to have initiated the field of angiogenesis, but it was really a decade before the international scientific community woke up to implications of these discoveries. Of the 33 angiogenesis 
publications between 1971 and 1976, Folkman was coauthor of more than half! From 1970 to 1980 there were only 65 publications with angiogenesis in the title and merely 135 with angiogenesis as a keyword.

The lack of bioassays for angiogenesis, the inability to culture endothelial cells invitro, and the absence of angiogenesis regulatory molecules confounded development [33]. Throughout the 1970's Folkman's group set out to develop reagents and methods that would allow investigators to isolate proangiogenic and antiangiogenic factors and provide supporting evidence for their struggling hypothesis [27].

Having suggested that a diffusible mediator or "angiogenic factor" existed that stimulated vascularisation Folkman and his colleagues had to find it! They struggled to assess potential isolated angiogenic molecules from tumour extracts due to inadequate experimental techniques available [27]. This experimental technique problem was eventually solved by Robert Langer, another of Folkman's postdoctoral fellows, who along with another group led by Robert Auerbach developed a polymer polyhydroxy ethy lmethacrylate (polyHEMA). This allowed implantation of the proteins of interest onto the mouse cornea in polymer pellets to detect angiogenic effects $[40,41]$.

One of the major steps in allowing scientific appreciation of the role of angiogenesis in tumour formation and demonstrating angiogenesis invitro was developing techniques that allowed long term passage of endothelial cells. This was first reported in 1973, independently by both Folkman's laboratory [35-37] and by Eric Jaffe at Cornell University, Ithaca, New York, USA [42]. However, it was not until 1979 that long-term passage of cloned endothelial cells was reported [43] and a year later angiogenesis invitro was demonstrated [44].

Later in 1979 they made an important step in confirming the hypothesis that removal of an angiogenic stimulus led to neovascularisation regression [45].

From these observations it was possible to elucidate that angiogenesis occurred in a continuum but could be divided into discrete stages for explanation. At this point the field of angiogenesis research bloomed but 10 years later than what Folkman may have expected in 1971.

Numerous growth factors and cytokines are now known to play an important role in the regulation of angiogenesis. Many factors that promote angiogenesis in bioassays were identified from 1980s onwards, including EGF, TGF-alpha, aFGF, bFGF, and angiogenin. Unfortunately linking these factors to angiogenesis in tumour models using neutralising antibodies or expression analyses yielded negative results [46]. However this changed from 1983, with the next major discovery in angiogenesis.

\section{Vascular Permeability Factor, or Is It Vascular Endothelial Growth Factor}

After the developments of the late 1970's many other scientists entered the field of angiogenesis and Folkman's skeptics "became his competitors" [28]. In 1983 Harold Dvorak and colleagues at Harvard Medical School discovered a potent angiogenic factor [47]. The authors purified what they called "vascular permeability factor" (VPF) from a guinea pig tumour cell line that promoted blood-vessel leakage and subsequent ascites. They proposed that this VPF may be a mediator of tumour blood vessel permeability. However they could not completely purify this VPF at the time, so it was not fully identified [46]. In 1989 this VPF was unknowingly revisited by three independent lines of research. Napoleone Ferrara purified a novel angiogenic protein from cow pituitary cells which he termed "vascular endothelial growth factor." This "VEGF" displayed growth-promoting activity towards only vascular endothelial cells [48]. At the same time in Folkman's laboratory, Rosenthal had isolated and purified to homogeneity an angiogenic protein that, when compared with the sequenced protein from Ferrara's research, was identical [27]. By 1990 it had become apparent that VEGF and VPF were in fact identical, as a team led by Daniel Connolly from Monsanto Company had followed up on the work by Dvorak and purified and sequenced VPF [49]. The first reported VEGF ligand identified from a tumour was published in a paper coauthored by Folkman and Ferrera in 1990 [50].

The first successful treatment of an angiogenesis-dependant tumour was in 1988 and reported in 1989 by Carl White, a pulmonary specialist at the National Jewish Medical Centre in Denver, Colorado, USA [28]. He had contacted Folkman for advice in the treatment of a teenager who had progressive bilateral pulmonary hemangiomatosis. All treatment avenues had failed and the condition was rapidly becoming fatal. Folkman suggested a trial of low dose interferon-alpha, based on its antiangiogenic experimental properties. The patient had a complete response and was still alive 18 years later [27]. Some years later in 2002 at a keynote lecture to the American Society of Law, Folkman expressed his gratitude to the Institutional Review Board at Boston's Children's Hospital for approving the use of interferon-alpha in the treatment of life-threatening haemangiomas. He stated that "from 1990 to 2000, 83 infants were treated with 72 complete and durable regressions - 87 percent now off therapy up to 9 years, eleven hemangiomas failed to regress, and six infants died." Explaining that "there have been no deaths in the past 3 years," 1999-2002, and that "prior to 1990, the mortality had been 30 to 50 percent in infants who failed conventional therapy. The addition of interferon alpha has reduced the overall mortality to less than 3 percent, and that's pretty much held up in other centers around the world."

Numerous angiogenesis inhibitors were discovered in Folkman's laboratory [27] and there are numerous new antiangiogenic molecules continuously being developed that fall into two distinct types, firstly antibody directed to wards angiogenic factors such as VEGF, for example, Avastin (Bevacizumab, Genentech) and secondly small molecule tyrosine kinases inhibitors that bind to VEGF receptors, for example, Sutent (Sunitinib, Pfizer) and Nexavar (Sorafenib, Bayer and Onyx Pharmaceuticals). Currently there are hundreds of ongoing clinical trials of antiangiogenic treatments within oncology and beyond with numerous therapeutic agents licensed for treatment. However despite important and sometimes dramatic results, the overall clinical benefits of antiVEGF therapy are relatively modest, and not all cancer patients respond to anti-VEGF treatments, and when they do increased survival may only be measured in weeks or months. 
Many trials are also underway in the adjuvant setting where it is hoped that these agents may slow or prevent disease remission.

There is no doubt however that angiogenesis is of paramount importance in the development of cancer and is an accepted target for anticancer therapy thanks to the dedicated, meticulous, and persistent nature of Folkman and his colleagues who overcame the scepticism of the scientific community towards the fledgling study of angiogenesis in the 1960s and 1970s.

Moses Judah Folkman died in 2008, having given many keynote lectures, publishing 463 scientific papers and numerous book chapters, and being highly decorated and recognised for his achievements. He has also inspired a generation of clinicians and researchers around the globe to believe in their theories and strive to make that breakthrough against the odds.

\section{Conflict of Interests}

The authors declare that they have no conflict of interests.

\section{References}

[1] A. P. Hall, "The role of angiogenesis in cancer," Comparative Clinical Pathology, vol. 13, no. 3, pp. 95-99, 2005.

[2] D. S. Torry, J. Leavenworth, M. Chang et al., "Angiogenesis in implantation," Journal of Assisted Reproduction and Genetics, vol. 24, no. 7, pp. 303-315, 2007.

[3] P. A. W. Rogers, S. Abberton, and B. Susil, "Endothelial cell migratory signal produced by human endometrium during the menstrual cycle," Human Reproduction, vol. 7, no. 8, pp. 10611066, 1992.

[4] A. Hertig, "Angiogenesis in the early human chorion and in the primary placenta of the Macque monkey," Contributions To Embryology, vol. 25, p. 37, 1935.

[5] G. Breier, "Angiogenesis in embryonic development-a review," Placenta, vol. 21, no. 1, pp. S11-S15, 2000.

[6] J. Hunter, The Works of John Hunter. Volume II. Observations in Comparative Anatomy, John van Voorst, London, UK, 1861.

[7] J. Hunter, The Works of John Hunter. Volume I. Essays and Observations on Natural History, John van Voorst, London, UK, 1861.

[8] K. Thiersch, Der Epithelialkrebs, namenthlich der Haut mit Atlas, Leipzig, Germany, 1865.

[9] R. Virchow, Die Krankhaften Geschwuste, August Hirschwald, Berlin, Geramny, 1863.

[10] C. A. T. Bilroth, "General surgical pathology and therapeutics," in Fifty Lectures. A Text-Book For Students and Physicians, D Appleton and company, New York, NY, USA, 1871.

[11] E. Goldmann, "The growth of malignant disease in man and the lower animals," The Lancet, vol. 170, no. 4392, pp. 1236-1240, 1907.

[12] E. Bashford, J. Murray, and W. Cramer, "The growth of cancer under natural and experimental conditions," Imperial Cancer Research Fund Scientific Reports, vol. 2, pp. 24-29, 1904.

[13] W. H. Lewis, "The vascular patterns of tumors," Bulletin of the Johns Hopkins Hospital, vol. 41, pp. 156-170, 1927.

[14] E. R. Clark and E. L. Clark, "Observations on living preformed blood vessels as seen in a transparent chamber inserted into the rabbit ear," American Journal of Anatomy, vol. 49, pp. 441-447, 1932.

[15] H. Ide, N. Baker, and S. Warren, "Vascularisation of the BrownPierce rabbit epithelioma transplant as seen in the rabbit ear chamber," American Journal of Roentgenological Radium Ther$a p y$, vol. 42, pp. 891-899, 1939.

[16] G. H. Algire, "An adaptation of the transparent-chamber technique to the mouse," Journal of the National Cancer Institute, vol. 4, pp. 1-11, 1943.

[17] G. H. Algire, "Microscopic studies of the early growth of a transplantable melanoma of the mouse, using the transparentchamber technique," Journal of the National Cancer Institute, vol. 4, pp. 13-20, 1943.

[18] G. H. Algire, H. W. Chalkley, and F. Y. Legallais, "Vascular Reactions of normal and malignant tumours in vivo. I. Vascular reactions of mice to wounds and to normal and neoplastic transplants," Journal of the National Cancer Institute, vol. 6, pp. 72-85, 1945.

[19] H. S. N. Greene, "Heterologous transplantation of mammalian tumors," Journal of Experimental Medicine, vol. 73, pp. 461-473, 1941.

[20] H. S. Greene, "The significance of the heterologous transplantability of human cancer," Cancer, vol. 5, no. 1, pp. 24-44, 1952.

[21] H. S. Greene, "A conception of tumor autonomy based on transplantation studies: a review," Cancer Research, vol. 11, no. 12, pp. 899-903, 1951.

[22] D. R. Cowdry and W. F. Sheldon, "The significance of hyperaemia around tumour transplants," American Journal of Pathology, vol. 22, p. 821, 1946.

[23] B. R. Lutz, D. I. Patt, A. H. Handler, and D. F. Stevens, "Serial sarcoma transplantation in the hamster cheek pouch and the effects of advanced neoplasia on the small blood vessels," Anatomical Record, vol. 108, p. 54, 1950.

[24] H. R. Bierman, K. H. Kelly, K. S. Dod, and R. L. Byron Jr., "Studies on the blood supply of tumors in man. I. Fluorescence of cutaneous lesions," Journal of the National Cancer Institute, vol. 11, no. 5, pp. 877-889, 1951.

[25] F. Urbach and J. H. Graham, "Anatomy of human skin tumour capillaries," Nature, vol. 194, no. 4829, pp. 652-654, 1962.

[26] P. Rubin and G. Casarett, "Microcirculation of tumors Part I: anatomy, function, and necrosis," Clinical Radiology, vol. 17, no. 3, pp. 220-229, 1966.

[27] J. Folkman, “Tumor angiogenesis: from bench to bedside," in Tumour Angiogenesis: Basic Mechanisms and Cancer Therapy, D. Marme and N. Fusenig, Eds., Springer, Heidelberg, Germany, 2007.

[28] H. L. Van Epps, "What tumors need: a brief history of angiogenesis," Journal of Experimental Medicine, vol. 201, no. 7, p. 1024, 2005.

[29] M. J. Folkman, D. M. Long, and F. F. Becker, "Tumor growth in organ culture," Surgical Forum, vol. 13, pp. 81-83, 1962.

[30] R. Cooke, Dr Folkman's War. Angiogenesis and the Struggle to Defeat Cancer, Random House, 2001.

[31] J. Folkman and D. M. Long, "The use of silicone rubber as a carrier for prolonged drug therapy," Journal of Surgical Research, vol. 4, no. 3, pp. 139-142, 1964.

[32] J. Folkman, "Tumor angiogenesis: therapeutic implications," New England Journal of Medicine, vol. 285, no. 21, pp. 1182-1186, 1971.

[33] J. Folkmann, "History of angiogenesis," in Angiogenesis: An Integrative Approach From Science to Medicine, W. D. Figg and J. Folkman, Eds., Springer, 2008. 
[34] M. A. Gimbrone Jr., S. B. Leapman, R. S. Cotran, and J. Folkman, "Tumor dormancy in vivo by prevention of neovascularization," Journal of Experimental Medicine, vol. 136, no. 2, pp. 261-276, 1972.

[35] M. A. Gimbrone Jr., S. B. Leapman, R. S. Cotran, and J. Folkman, "Tumor angiogenesis: iris neovascularization at a distance from experimental intraocular tumors," Journal of the National Cancer Institute, vol. 50, no. 1, pp. 219-228, 1973.

[36] M. A. Gimbrone Jr., R. S. Cotran, S. B. Leapman, and J. Folkman, "Tumor growth and neovascularization: an experimental model using the rabbit cornea," Journal of the National Cancer Institute, vol. 52, no. 2, pp. 413-427, 1974.

[37] M. A. Gimbrone Jr., R. S. Cotran, and J. Folkman, "Human vascular endothelial cells in culture. Growth and DNA synthesis," Journal of Cell Biology, vol. 60, no. 3, pp. 673-684, 1974.

[38] M. Greenblatt and P. Shubi, “Tumor angiogenesis: transfilter diffusion studies in the hamster by the transparent chamber technique," Journal of the National Cancer Institute, vol. 41, no. 1, pp. 111-124, 1968.

[39] R. L. Ehrmann and M. Knoth, "Choriocarcinoma. Transfilter stimulation of vasoproliferation in the hamster cheek pouch. Studied by light and electron microscopy," Journal of the National Cancer Institute, vol. 41, no. 6, pp. 1329-1341, 1968.

[40] V. Muthukkaruppan and R. Auerbach, "Angiogenesis in the mouse cornea," Science, vol. 205, no. 4413, pp. 1416-1418, 1979.

[41] R. Langer and J. Folkman, "Polymers for the sustained release of proteins and other macromolecules," Nature, vol. 263, no. 5580, pp. 797-800, 1976.

[42] E. A. Jaffe, R. L. Nachman, C. G. Becker, and C. R. Minick, "Culture of human endothelial cells derived from umbilical veins. Identification by morphologic and immunologic criteria," Journal of Clinical Investigation, vol. 52, no. 11, pp. 2745-2756, 1973.

[43] J. Folkman, C. C. Haudenschild, and B. R. Zetter, "Long-term culture of capillary endothelial cells," Proceedings of the National Academy of Sciences of the United States of America, vol. 76, no. 10, pp. 5217-5221, 1979.

[44] J. Folkman and C. Haudenschild, "Angiogenesis in vitro," $\mathrm{Na}$ ture, vol. 288, no. 5791, pp. 551-556, 1980.

[45] D. H. Ausprunk, K. Falterman, and J. Folkman, "The sequence of events in the regression of corneal capillaries," Laboratory Investigation, vol. 38, no. 3, pp. 284-294, 1978.

[46] N. Ferrara, "Vascular endothelial growth factor," Arteriosclerosis, Thrombosis, and Vascular Biology, vol. 29, no. 6, pp. 789-791, 2009.

[47] D. R. Senger, S. J. Galli, A. M. Dvorak, C. A. Perruzzi, V. Susan Harvey, and H. F. Dvorak, "Tumor cells secrete a vascular permeability factor that promotes accumulation of ascites fluid," Science, vol. 219, no. 4587, pp. 983-985, 1983.

[48] N. Ferrara and W. J. Henzel, "Pituitary follicular cells secrete a novel heparin-binding growth factor specific for vascular endothelial cells," Biochemical and Biophysical Research Communications, vol. 161, no. 2, pp. 851-858, 1989.

[49] P. J. Keck, S. D. Hauser, G. Krivi et al., "Vascular permeability factor, an endothelial cell mitogen related to PDGF," Science, vol. 246, no. 4935, pp. 1309-1312, 1989.

[50] R. A. Rosenthal, J. F. Megyesi, W. J. Henzel, N. Ferrara, and J. Folklman, "Conditioned medium from mouse sarcoma 180 cells contains vascular endothelial growth factor," Growth Factors, vol. 4, no. 1, pp. 53-59, 1990. 


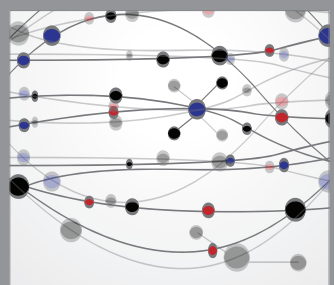

The Scientific World Journal
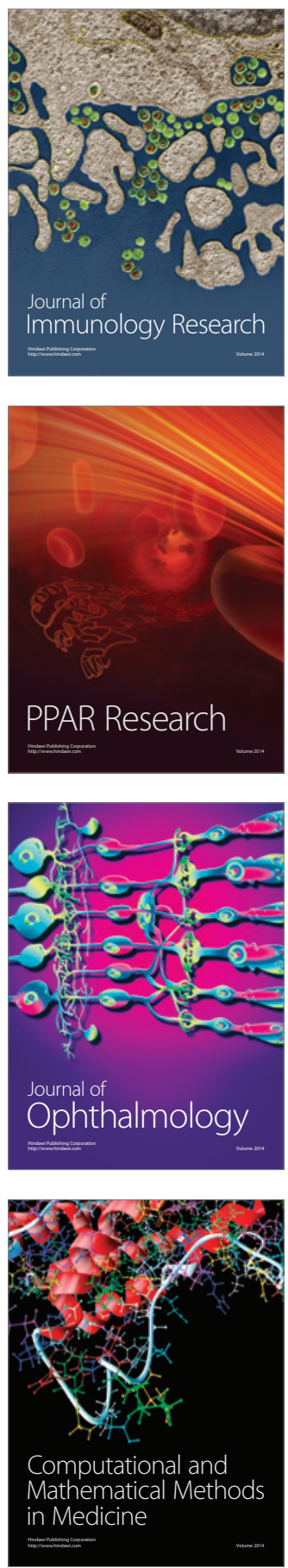

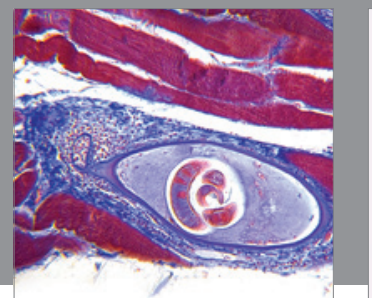

Gastroenterology

Research and Practice
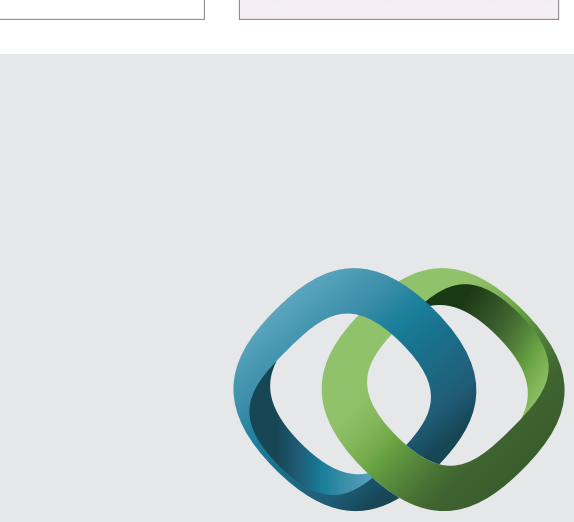

\section{Hindawi}

Submit your manuscripts at

http://www.hindawi.com
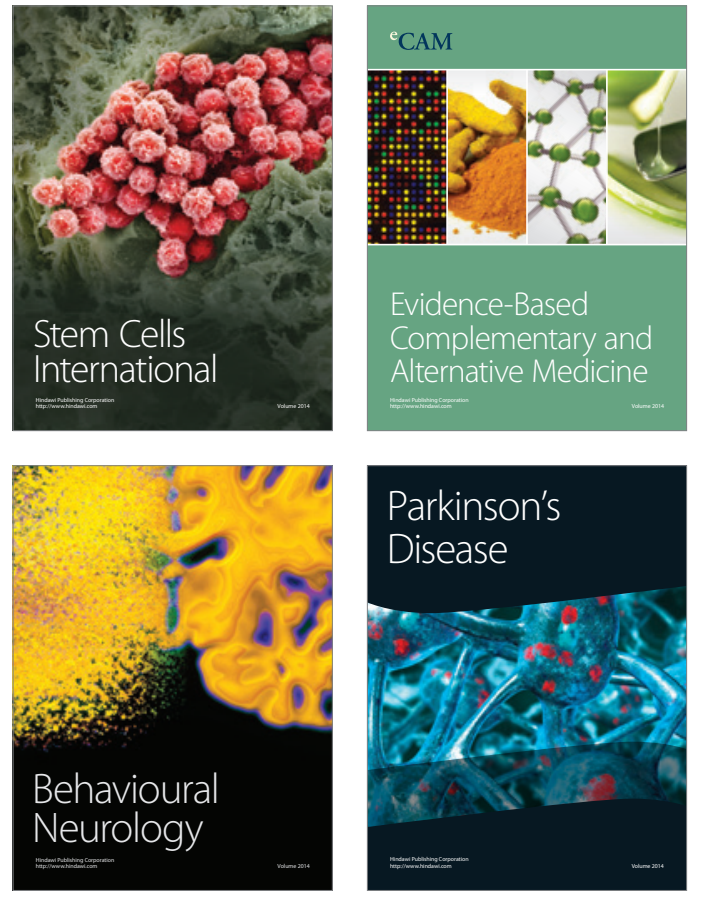
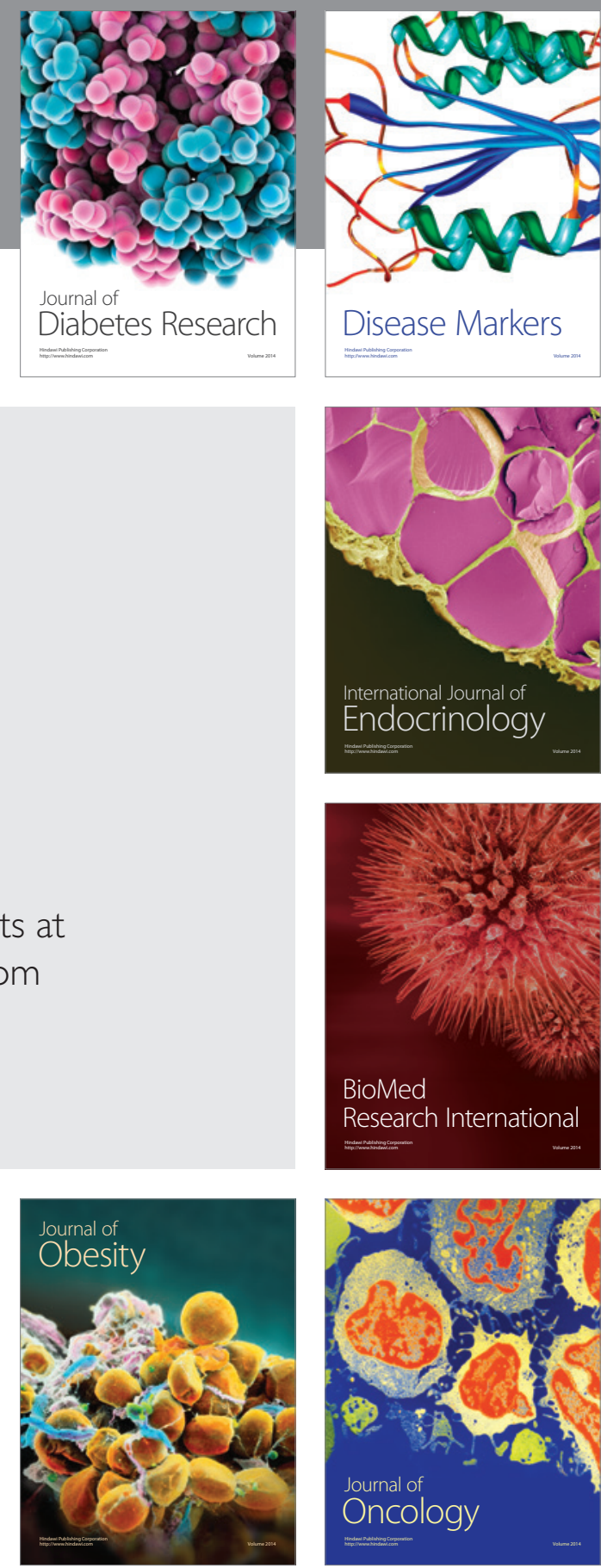

Disease Markers
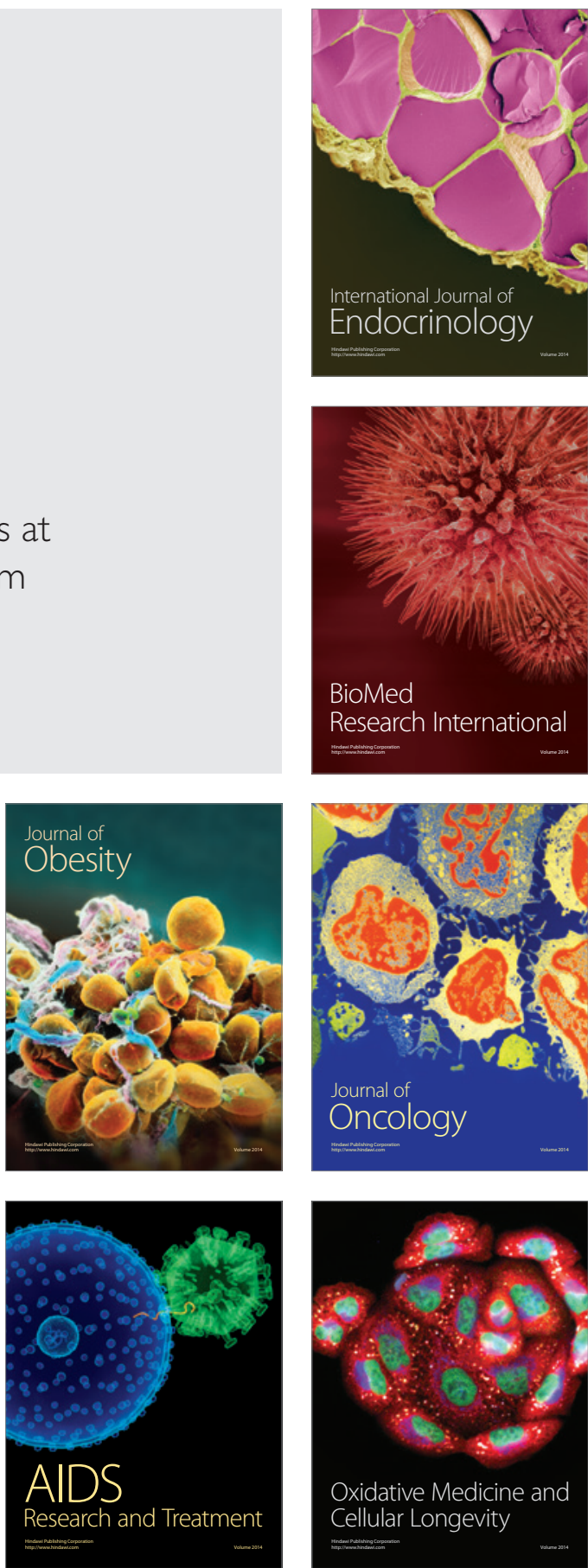